\title{
HOW TO USE THIS INDEX
}

This volume provides a guide to the 3,000 -odd films restored from the Library of Congress paper print collection, most of which contain a great deal of information for film and other historians. When we wrote this book it was our intention to provide a simple tool so that a student or historian could easily avail himself of the contents of the films.

There is more than one way of obtaining information about a film included in this collection. If you know the title, there is an alphabetical list beginning on page 384 . If you are seeking a film on a particular subject turn to the indexes beginning on page 357. If you want to locate film on a specific individual, see the list of celebrities on page 378 . The alphabetical list indicates the page number of the main entry, where the synopsis of the film will also be found.

Titles are given as they appear in Copyright Office records; where a different title is on the film, it is given at the end of the main entry. Occasionally a mishap occurred when a producer sent in two films at the same time and it is quite obvious from the content of the film that the titles became transposed. Each such instance is mentioned.

In every case we used the Library of Congress copyright date and number and in any communication with the Library this information should be included.

When the restoration program began, the Academy of Motion Picture Arts and Sciences suggested that a name be given to the process used for restoring the paper prints in the interest of better identification. The name chosen, "Renovare," is a Latin word meaning "to restore." As the paper rolls came to us from the Library of Congress, each was assigned a Renovare inventory and production number which we then photographed into the "leader" of each film.

Our selection of categories is of course somewhat arbitrary, but we used the term that gave us the opportunity of placing the greatest number of films in a particular classification. For example, when we viewed a drama or comedy where automo- 
biles, trains, or ships were visible, the film was then crossreferenced under each of these categories as well as under its main-entry classification. In some instances, we found it advisable to develop special categories, such as for the films that D. W. Griffith made at Biograph, reproductions (as reconstructions were then termed) of news events, or comedies in which Mary Pickford appeared. The curious fact that only one film appears in the Medical category, although many copyright applications were filed for medical films, can be attributed to two possible causes: either no paper prints were sent in, or none survived.

Halfway through the film classification process we began to encounter pairs of variations of the same film. This happened when a competitive firm modified another company's plot, or when different employees of the original producer made a different version, many times on the same day. These seemed to constitute a body of film deserving special study in itself, because of its bearing on the development of early narrative techniques. Hence these titles are catalogued separately under Comedy (Another Version), although they also appear in the very large Comedy category. A few films included in the Reproductions category also appear in the Newsreel or Documentary categories, and a few films unavoidably overlap in other categories.

Films classified as "peep shows" were, to the best of our knowledge, never projected but seen only in peep-hole viewing devices.

We used the word "series" to describe those films where a repertory group made one complete film after another with a different plot; whereas in a "serial," the film was never completed between the climax of one and the beginning of another.

A separate index category was made of "Unusual Camera Uses" simply because through the half century this machine has been used as a tool, stories about who first was responsible for the development of its many processes have grown out of all proportion. Fades, wipes, dissolves, cutbacks, dolly movements, and close-ups, terms indigenous to the moving picture, all are represented in these early works and are classified as "Unusual Camera Uses" to give the student an opportunity to judge for himself the accuracy of film history.

All films included in this index may be considered to be in good condition unless rated "fair" or "poor" on the main entry sheet. "Fair" means action can be established and that the objects are visually separated from one another. "Poor" indi- 
cates the activity in the film is barely discernible. All of the paper duplicates were completed to the best of our ability regardless of clarity of image.

Every time we looked at a film, a summary was made as well as classifications assigned, but in no case was the synopsis intended as a critique of the film. The synopsis represents only what we actually saw in the film and not what others have said the film contained. For example, our research uncovered contemporary handbills and trade publications with advertisements intended for the film buyer. In most instances, these tended to elaborate rather than be factual and once in a while even the captions under the photographs were incorrect.

Another oddment that came to light was the lack of consistency between date of production, date of copyright, and date of film release. One needs only to consider the difficulty in transportation and communication during this era to get an explanation for this variation. Generally speaking, though, the period between date of production and date of release rarely exceeded 30 days.

Modern film-goers are accustomed to seeing names of the cast included in screen credits. Twenty years of film production had passed, however, before this became common practice. A great deal of effort was expended to identify as many of the cast as possible in these films. The usual historical inconsistencies existed in this area, too, so we have used the name as it most commonly appeared in such sources as contemporary trade magazines. For instance, Linda Arvidson (Mrs. D. W. Griffith) used the name Linda Griffith in her later screen career. Herbert Yost was also known as Barry O'Moore. Other names with one or more spelling are Harry Salter (Solter), John Compson (Cumpson), and Frank Grandin (Francis Grandon).

Production companies that sent paper duplicates to the Library of Congress for copyright protection are listed alphabetically on page xvii. Abbreviations are used in the main entries for the American Mutoscope \& Biograph Company (later incorporated as the Biograph Company), and a few others. In any project of this magnitude, there must be some inconsistencies. One such is a collection of 16 films copyrighted under the name of Ingvald C. Oes, the American representative of the Nordisk Film Company.

Another inconsistency is the inclusion of a few 1914 and 1915 films made by Klaw \& Erlanger and the New York Motion Picture Company. These films were restored under the 
Paper Print Program even though the paper duplicates came to the Library of Congress after the motion picture copyright law was ratified. Klaw \& Erlanger was a vaudeville booking organization that made films under the auspices of the Biograph Company, while the New York Motion Picture Company films were produced and directed for them by Thomas H. Ince. 